\title{
Ethylene Yield from a Large Scale Naphtha Pyrolysis Cracking Utilizing Response Surface Methodology
}

\author{
Mohamad Hafizi Zakria ${ }^{1,2 *}$, Mohd Ghazali Mohd Nawawi ${ }^{1}$ and Mohd Rizal \\ Abdul Rahman ${ }^{2,3}$ \\ ${ }^{1}$ School of Chemical and Energy Engineering, Faculty of Engineering, Universiti Teknologi Malaysia, \\ 81310 Johor, Malaysia \\ ${ }^{2}$ Manufacturing and Engineering Division, Pengerang Refining Company Sdn Bhd, PICMO B2, \\ Pengerang Integrated Complex, 81600 Johor, Malaysia \\ ${ }^{3}$ Group Technical Solutions, Petroliam Nasional Berhad (PETRONAS), The Intermark Tower, \\ 55000 Kuala Lumpur, Malaysia
}

\begin{abstract}
Statistical software is a robust application that has proven reliable worldwide. However, it is not normally used in the actual large scale olefin plant as it relies on the simulation software by Olefin Licensor should any issue rises. The study was conducted in a newly commissioned large scale olefin plant to see the impact of various operating variables on the ethylene yield from Short Residence Time (SRT) VII Furnace. The analysis was conducted utilizing statistical analysis, Response Surface Methodology (RSM) in Minitab Software Version 18 to develop a reliable statistical model with a 95\% confidence level. The historical data was taken from the Process Information Management System (PIMS) Software, PI Process Book Version 2015, and underwent both residuals and outliers removal prior to RSM analysis. 10 variables were shortlisted from the initial 15 identified variables in the studied SRT VII via Regression analysis due to RSM

ARTICLE INFO

Article history:

Received: 16 November 2020

Accepted: 22 February 2021

Published: 30 April 2021

DOI: https://doi.org/10.47836/pjst.29.2.06

E-mail addresses:

fizietranung@gmail.com; mohamadhafizi.zakri@prefchem.com (Mohamad Hafizi Zakria)

ghazalinawawi@utm.my (Mohd Ghazali Mohd Nawawi)

mohdrizal@petronas.com.my (Mohd Rizal Abdul Rahman)

* Corresponding author limitation to conduct the larger analysis in Minitab Software Version 18. The Response Optimizer tool showed that the ethylene yield from naphtha pyrolysis cracking in the studied plant could be maximized at $34.1 \%$ with control setting at $600.39 \mathrm{~kg} /$ hr of Integral Burner Flow, 6.81\% of Arch $\mathrm{O}_{2}, 113.42$ Barg of Steam Drum Pressure,
\end{abstract}


$496.96^{\circ} \mathrm{C}$ of Super High Pressure (SHP) Temperature, $109.11 \mathrm{t} / \mathrm{hr}$ of SHP Boiler Feed Water (BFW) Flow, 92.78 t/hr of SHP Flow, $63.50 \mathrm{t} / \mathrm{hr}$ of Naphtha Feed Flow, and -13.38 mmHg of Draft Pressure.

Keywords: Ethylene yield, naphtha cracking, olefin plant, pyrolysis cracking, response surface methodology, statistical analysis

\section{INTRODUCTION}

Thermal and catalytic cracking are the mature technologies in producing polymer grade olefins from gaseous and liquid feedstock such as ethane, propane, naphtha, and gasoil (Fakhroleslam \& Sadrameli, 2019, 2020; Sadrameli, 2015; Sadrameli, 2016). These feedstocks are available from various sources worldwide and may be applied to various technologies in producing olefins (Fakhroleslam \& Sadrameli, 2019).

Apart from well-known thermal and catalytic cracking technologies, there are also other technologies being studied for olefins production such as propane dehydrogenation (Akporiaye et al., 2001; Darvishi et al., 2016), Fluidized Catalytic Cracking (FCC) (Sadrameli, 2016), olefin metathesis (Astruc, 2005), and reaction optimization in FCC process (Akah \& Al-Ghrami, 2015). However, they are not widely applied to industrial applications to produce olefins due to the higher production cost (Fakhroleslam \& Sadrameli, 2019).

Thermal cracking or also known as pyrolysis cracking in the olefin industry causes hydrocarbon bonds to break and resulting in the formation of the desired small and unsaturated molecule (Van de Vijver et al., 2015; Vangaever et al., 2020) such as olefins. Ethylene is an example of an olefin product that is produced from high-temperature pyrolysis cracking reaction (Shi et al., 2015; Song et al., 2019; Van de Vijver et al., 2015; Vangaever et al., 2020).

The pyrolysis cracking process in the steam cracker furnace is divided into three main sections normally referred to as radiation, convection, and flue gas stack (Fakhroleslam \& Sadrameli, 2019; Fakhroleslam \& Sadrameli, 2020; Karimzadeh et al., 2009; Sadrameli, 2015; Sadrameli, 2016). Over the years, numerous improvements have been established to improve the process efficiencies to these three sections in the steam cracker furnace to achieve the higher ethylene yield (Belinskaya et al., 2019; Han et al., 2016; Peller et al., 2018; Podrojková et al., 2018).

This study was conducted in the actual large scale plant with naphtha liquid as a feedstock to the steam cracker furnace utilizing pyrolysis cracking technology. The studied steam cracker furnace was Short Residence Time (SRT) VII from ABB Lummus, designed to produce 1,100 KTA capacity of polymer grade ethylene product. SRT VII is among the most promising technology available in the market proven reliable and efficient in producing the olefins (Caballero et al., 2015; Kuritsyn et al., 2008). 
The study in the actual large scale plant is challenging as it is often affected by various process fluctuation (Feli et al., 2017; Zakria et al., 2016) due to frequent process variation in the feedstock composition, upstream plant performance, downstream readiness, and utility availability. Figure 1 shows the configuration of the SRT VII and its auxiliaries in the studied plant.

The plant was designed to process the continuous naphtha feed from the upstream plant. The feed enters the furnace and mixes with Dilution Steam (DS) in the convection section. The mixing is initiated at the start of the process to improve olefin selectivity by reducing the partial pressure of naphtha feed (Karimi et al., 2017; Masoumi et al., 2006) and favors the ethylene yield from the reversible reaction following Le' Chatelier's Principles (Cai et al., 2017; Epstein, 1978).

The mixed feed from the convection section flows into the radiation section with the operating Tube Metal Temperature (TMT) of $1,050{ }^{\circ} \mathrm{C}-1,180{ }^{\circ} \mathrm{C}$. This extremely high temperature is supplied to the SRT VII to maximize the ethylene yield generation. The cracked gas from the radiation section then will flow into the Transfer Line Exchanger (TLE) for rapid cooling of effluent and generation of Super High Pressure (SHP) Steam. The SHP steam generated from TLE will be used at the downstream process to drive the Charge Gas Compressor (CGC).

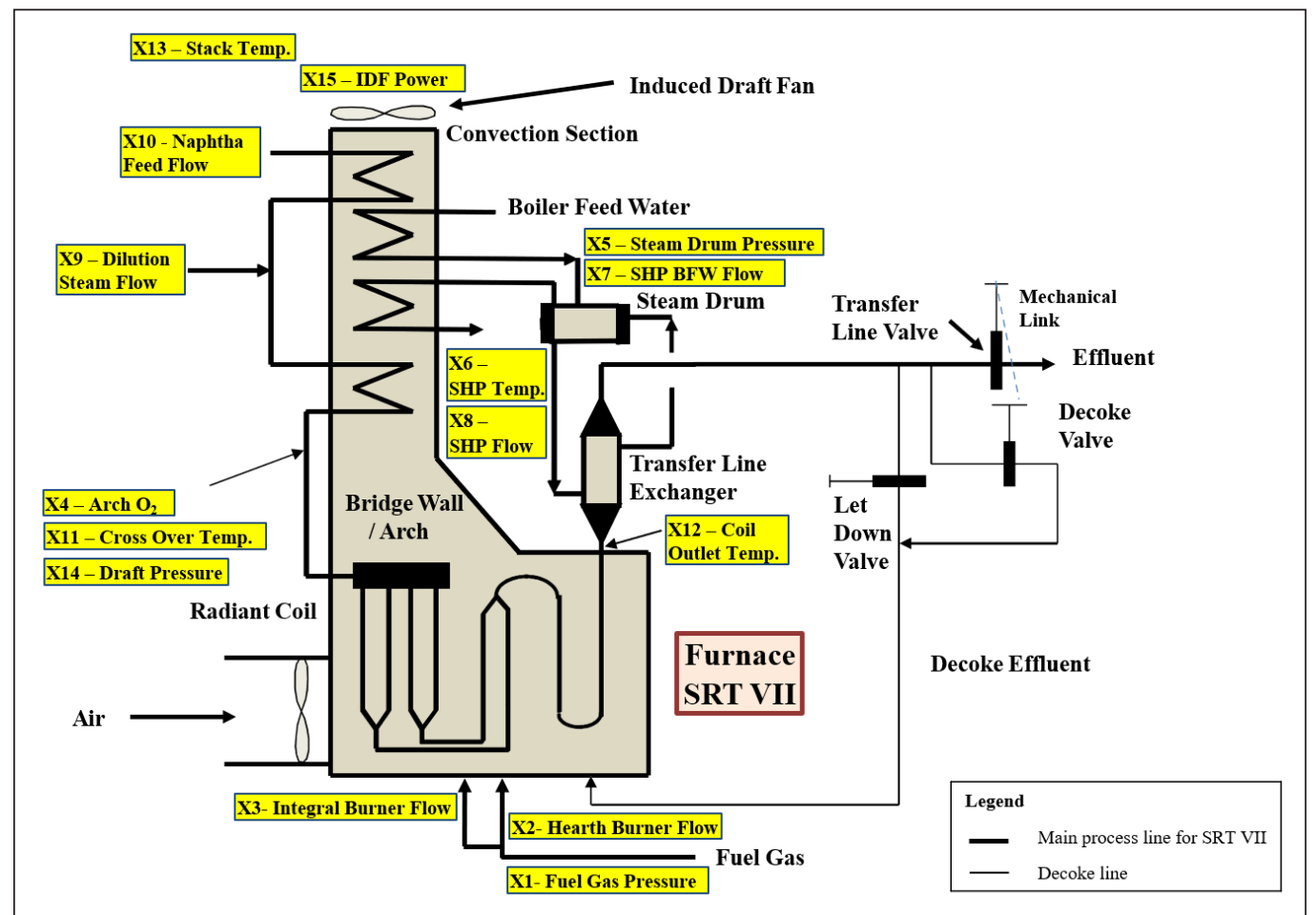

Figure 1. General arrangement for SRT VII at the studied plant inclusive of tags and descriptions for the selected variables 
Various studies have been conducted from simulation, lab experiments and pilot scale plants that looking at various process parameters to optimize the olefins yield such as ethylene from the furnace. The specific control variables such as Coil Outlet Temperature (COT) (Song \& Tang, 2018; Yu et al., 2018), Dilution Steam ratio (Berreni \& Wang, 2011; Geng et al., 2016), naphtha feedstock (Geng et al., 2016; Nian et al., 2015) and fuel gas consumption (Yu et al., 2018) were normally studied to optimize the olefins yield. However, there is also an opportunity to explore other variables in the steam cracker furnace which are not widely discussed such as Arch $\mathrm{O}_{2}$, Steam Drum, and Draft Pressure to see their relations towards the olefins yield.

Response Surface Methodology (RSM) is the mathematical and statistical techniques used to model and analyze problems where the responses are influenced by a few factors for optimization (Montgomery, 2017). The method has proven successful in a number of recent studies conducted for various subjects (Amirov \& Vakhshouri, 2020; Reddy et al., 2020; Sun et al., 2016a; Sun et al., 2016b).

However, RSM application in large scale olefin plants is not common. The industrial olefin plant usually relies on the process simulation provided by the specific Olefin Licensor in the market should any issue rises such as ABB Lummus, KTI-Technip, Linde AG (Pyrocrack), Stone and Webster, and M.W. Kellogg (Sadrameli, 2015). Examples of currently available software are SPYRO (Dente et al., 1979; Van Goethem et al., 2001), SHAHAB (Toufighi et al., 2004), CRACKER (Joo et al., 2000; Joo \& Park, 2001), CHEMKIN (Kee et al., 2006; Reyniers et al., 2017; Van Cauwenberge et al., 2017) and CRACKSIM (Hillewaert et al., 1988; Van Geem et al., 2008; Willems \& Froment, 1988).

Normally, the simulation software comes with its own limitation such as robust simulation only applicable for specific furnace section such as radiation or convection section only. Some Olefin Licensor also provides the simulation software with a limited number of licenses for the olefin plant with a high price, and normally does not come will full access to safeguard the proprietary olefin plant design. This often makes the process monitoring and its troubleshooting for the olefins plant worldwide difficult. The optimization of ethylene yield via a systematic approach is challenging if the worldwide large scale olefin plant fully relies on the limited access and complex software by Olefin Licensor alone.

This study is significant in closing the gap in providing a practical solution (economical, process width, and easy application) for process monitoring and troubleshooting at the actual large scale olefin plant. It provides a guideline to the Panel Operators and Technologists in the studied plant to develop the maximized ethylene yield model based on a set of actual historical data from the large scale olefin plant using RSM in Minitab Software. Besides, this study also closes the gap in showing the impact of the other parameters that are not widely discussed at the large scale steam cracker furnaces such as $\mathrm{Arch}_{2}$, Steam Drum Pressure, and Draft Pressure. 


\section{METHODS AND EQUIPMENT}

\section{Equipment/Tools}

The study utilized the newly commissioned SRT VII furnace with its auxiliaries comprised of main components such as TLEs, Burners, Steam Drum, and Induced Draft Fan (IDF). The steam cracker furnace was designed with $93 \mathrm{t} / \mathrm{hr}$ of processing capacity for naphtha liquid by Lummus Technology Heat Transfer (LTHT), United States, and constructed by Toyo Engineering, Japan.

The data used for the analysis was extracted based on actual plant data during the Start of Run (SOR) condition from the Process Information Management System (PIMS) Software, PI Process Book Version 2015 while the analysis was conducted using RSM in Minitab Software Version 18.

\section{Methods}

Table 1 shows 15 variables associated with the studied SRT VII furnace with the dedicated tag namely X1 -X15. The specific location of each tag was shown in Figure 1. The tags were chosen without segregation of "controlled" and "output" variables to see the relation of all variables towards Ethylene Yield represented by Y1.

Although these 15 variables covering almost all parameters in the studied steam cracker furnace, the environmental impacts such as $\mathrm{SO}_{\mathrm{X}}$ and $\mathrm{NO}_{\mathrm{X}}$ emissions at the furnace stack were excluded as the environmental aspect was not prioritized for this study.

The date for analysis was selected on January 24, 2020, 1700 hrs to February 2, 2020, $1200 \mathrm{hrs}(211 \mathrm{hrs})$. The data was extracted as an hourly (average, time weighted) from the PI Process Book with a total of 3,376 data (represented by 1 output and 15 input variables). The data used for analysis focused on the Ethylene Yield at the normal operating range of the studied plant which was $28.70 \%$ to $30.67 \%$. This small range was selected to safeguard the plant safety and equipment integrity during the study as advised by the olefin plant licensor.

The Paraffins, Olefins, Naphthenes, and Aromatics (PONA) composition in Naphtha feedstock were $60.92 \%$ vol, $1.02 \%$ vol, $25.97 \%$ vol, and $12.09 \%$ vol respectively. The Initial Boiling Point (IBP) and Final Boiling Point (FBP) for the naphtha feedstock were $34.1^{\circ} \mathrm{C}$ and $166.1^{\circ} \mathrm{C}$ respectively.

Box Plot, Run Chart, and Individual-Moving Range (I-MR) Chart were used for the data stability verification while the Normality Test and Graphical Summary were used to check on the data normality for these 3,376 data. The P-Value in both stability and normality verification for these tools was ensured at above 0.05 to proceed as normal data in the Regression and RSM analysis. The analysis may utilize the Box-Cox data transformation methodology if the P-Value generated from stability and normality verification was lower than 0.05 . 
Regression analysis was initiated to all 15 identified variables before the RSM analysis to shortlist only 10 most significant variables. This step was taken due to the limitation in Minitab Software Version 18 in handling the bigger analysis for RSM. The Regression was conducted a few times, via one by one variable elimination in each Regression to remove insignificant variables with VIF $>10$ and P-Value $>0.05$.

The variable elimination followed the sequence which started from the highest VIF value until all variables achieved VIF $<10$. After all of the remaining variables were determined at $\mathrm{VIF}<10$, the elimination continued for variables starting from the highest P-Value until only 10 variables left in the intermediate Regression for further analysis using RSM.

RSM was conducted to the remaining 10 variables via the Historical Design of Experiment (DOE) method. The intervals were set at 95\% in the Minitab (Analyze Response Surface Design interface setting) to ensure the analysis was conducted at the $95 \%$ of confidence level. The elimination of the insignificant variables was also conducted in RSM one by one, started from the Two-ways Interaction, Square, and finally to the Linear relation. This sequence was essential to maintain the hierarchical model in RSM.

The elimination in RSM also started from the highest VIF and P-Value until all VIF $<10$ and P-Value $<0.05$ achieved. VIF measures the severity of multicollinearity that exists in the ordinary least squares Regression analysis. VIF $>10$ is not recommended (Hair et al., 1995) due to its multicollinearity relation which may affect the P-value and finally contribute to the unreliable model. However, the variable with a higher VIF and P-Value in Linear relation may be considered into the final model should the variable exist in the model as Square or Two-Way Interaction to maintain the hierarchical RSM model. This must also be supported by a good R-Square at $75 \%$ or higher.

The validation for the final RSM equation model was conducted using the Probability Plot for the residuals. The residuals in the Probability Plot represented the difference between the predicted data from the final equation model versus the actual plant data in the studied plant. This plot was important in measuring the degree of regression line vertically might miss a data point. The P-Value of higher than 0.05 in the Probability Plot was a good validation criterion for the reliable final equation model for the Historical DOE method in RSM.

Surface Plot was also utilized for four variables with the highest impact which was determined from the highest coefficient factor in the final equation model. Surface Plot is important to surface the relation and contribution of two continuous variables towards the fitted response value of ethylene yield in form of a three-dimensional view in Minitab Software.

Finally, the Response Optimizer tool was applied to the final model to predict the maximum value of ethylene yield with the process settings for the identified significant 
variables in RSM analysis. The setting in Response Optimizer was useful as a guideline for the studied olefin plant to maximize the predicted response of the ethylene yield.

\section{RESULTS AND DISCUSSION}

Table 1 shows the $1^{\text {st }}$ Regression (initial) and $6^{\text {th }}$ Regression (intermediate) that were conducted to select only 10 variables for RSM analysis.

The $1^{\text {st }}$ Regression was started to establish the overall relationship between each variable. The $2^{\text {nd }}$ Regression was continued with the elimination of variables with VIF $>10$. From the analysis, the VIF for all variables successfully reduced to $<10$ after the $2^{\text {nd }}$ Regression. Besides, some variables with VIF $>10$ in $1^{\text {st }}$ Regression such as X10 was successfully reduced to 9.68 in the $2^{\text {nd }}$ Regression and therefore these variables remained in the intermediate regression. This condition occurred due to the multicollinearity factors for X10 was reduced as the first variable, X13 removed from the analysis.

The $3^{\text {rd }}-6^{\text {th }}$ Regressions were conducted with the removal of variables with P-Value $>0.05$. The $6^{\text {th }}$ Regression was determined as the intermediate Regression as 10 variables were successfully shortlisted. The sequence of elimination for $2^{\text {nd }}-6^{\text {th }}$ Regression conducted were X13 (VIF: 17.54), X9 (P-Value: 0.759), X1 (P-Value: 0.720), X15 (P-Value: 0.542), and X11 (P-Value: 0.564$)$. This one by one variable elimination was taken to ensure only

Table 1

Identified 10 variables for the RSM analysis

\begin{tabular}{|c|c|c|c|c|c|c|c|c|}
\hline \multirow{2}{*}{\multicolumn{2}{|c|}{ Tag with Description }} & \multicolumn{3}{|c|}{ Initial (1 ${ }^{\text {st }}$ Regression) } & \multicolumn{3}{|c|}{ Intermediate ( $6^{\text {th }}$ Regression $)$} & \multirow{2}{*}{$\begin{array}{c}\text { New } \\
\text { RSM } \\
\text { Tag }\end{array}$} \\
\hline & & \multirow{2}{*}{$\begin{array}{c}\text { Coef. } \\
-1.3\end{array}$} & \multirow{2}{*}{$\begin{array}{c}\text { P-Value } \\
0.976\end{array}$} & & \multirow{2}{*}{$\frac{\text { Coef. }}{4.4}$} & \multirow{3}{*}{$\begin{array}{c}\text { P-Value } \\
0.883\end{array}$} & \multirow[t]{2}{*}{ VIF } & \\
\hline Cons & ant & & & & & & & \\
\hline $\mathbf{X} 1$ & Fuel Gas Pressure & 0.049 & 0.850 & 3.02 & & & & \\
\hline $\mathbf{X} 2$ & Hearth Burner Flow & -0.000852 & 0.000 & 8.50 & -0.000917 & 0.000 & 7.20 & $\mathbf{A}$ \\
\hline $\mathbf{X} 3$ & Integral Burner Flow & 0.02804 & 0.000 & 2.59 & 0.02937 & 0.000 & 2.41 & B \\
\hline $\mathbf{X} 4$ & $\operatorname{Arch~} \mathrm{O}_{2}$ & -0.281 & 0.094 & 3.72 & -0.234 & 0.111 & 2.89 & $\mathbf{C}$ \\
\hline X5 & Steam Drum Pressure & -0.420 & 0.004 & 4.41 & -0.443 & 0.002 & 4.14 & D \\
\hline X6 & SHP Temperature & -0.0254 & 0.237 & 3.49 & -0.0211 & 0.290 & 3.05 & $\mathbf{E}$ \\
\hline $\mathbf{X} 7$ & SHP BFW Flow & 0.1537 & 0.000 & 5.17 & 0.1617 & 0.000 & 4.06 & $\mathbf{F}$ \\
\hline X8 & SHP Flow & -0.0696 & 0.013 & 3.05 & -0.0768 & 0.003 & 2.66 & $\mathbf{G}$ \\
\hline X9 & Dilution Steam Flow & -0.000031 & 0.801 & 1.10 & & & & \\
\hline $\mathbf{X 1 0}$ & Naphtha Feed Flow & 0.1400 & 0.000 & 10.96 & 0.1112 & 0.000 & 6.83 & $\mathbf{H}$ \\
\hline X11 & Crossover Temperature & -0.0007 & 0.991 & 9.93 & & & & \\
\hline $\mathbf{X} 12$ & Coil Outlet Temp. & 0.0766 & 0.156 & 3.21 & 0.0797 & 0.049 & 1.83 & $\mathbf{J}$ \\
\hline X13 & Stack Temperature & 0.0888 & 0.362 & 17.54 & & & & \\
\hline X14 & Draft Pressure & 0.126 & 0.305 & 1.40 & 0.131 & 0.243 & 1.20 & $\mathbf{K}$ \\
\hline X15 & ID Fan Power & -0.0401 & 0.391 & 2.14 & & & & \\
\hline
\end{tabular}


insignificant variables were removed as the VIF and P-Value will significantly change after each variable eliminated from the analysis.

RSM analysis continued with the new tags for the identified 10 variables in the intermediate Regression. The new tags were named A - K as shown in Table 1. These changes were necessary to avoid confusion in the RSM analysis as 10 variables in RSM analysis resulted in a total of 45 Two-Way Interactions, 10 Squares, and 10 Linear relations.

The R-Square from the final model was good at $87.22 \%$ regardless it was conducted in the actual large scale plant where process fluctuation often occurred. This value translated to $87.22 \%$ of the variability in data was accounted for in the model. It is adequate the meet the data variability which is advised at more than 75\% (Haaland, 1989; Omar et al., 2009). Table 2 shows the details of the Analysis of Variance (ANOVA) for the RSM analysis.

The remaining 15 degree of freedoms (DFs) in Table 2 indicated that a total of 41 Two-Way Interactions, 7 Squares, and 2 Linear relations were removed during one by one variable elimination. Some variables with P-Value $>0.05$ were retained in the final model which were E (SHP Temperature), and K (Induced Draft Fan Power). These variables were accepted to maintain the hierarchical RSM model as their relation also existed in the Square

Table 2

ANOVA for the final RSM model

\begin{tabular}{ccccccc}
\hline Source & DF & Adj SS & Adj MS & F-Value & P-Value & VIF \\
\hline Model & 15 & 26.2656 & 1.75104 & 70.54 & 0.000 & \\
\hline Linear & 8 & 7.7088 & 0.96360 & 38.82 & 0.000 & \\
B & 1 & 0.4423 & 0.44228 & 17.82 & 0.000 & 2.32 \\
C & 1 & 0.3016 & 0.30155 & 12.15 & 0.001 & 7.26 \\
D & 1 & 2.2811 & 2.28106 & 91.89 & 0.000 & 4.68 \\
E & 1 & 0.0415 & 0.04148 & 1.67 & 0.198 & 2.32 \\
F & 1 & 0.1801 & 0.18006 & 7.25 & 0.008 & 5.12 \\
G & 1 & 0.2121 & 0.21208 & 8.54 & 0.004 & 3.45 \\
H & 1 & 0.4239 & 0.42394 & 17.08 & 0.000 & 8.04 \\
K & 1 & 0.0845 & 0.08452 & 3.40 & 0.067 & 1.30 \\
\hline Square & 3 & 1.5394 & 0.51313 & 20.67 & 0.000 & \\
C*C & 1 & 0.7332 & 0.73324 & 29.54 & 0.000 & 1.40 \\
D*D & 1 & 0.4887 & 0.48868 & 19.69 & 0.000 & 2.01 \\
E*E & 1 & 0.1521 & 0.15212 & 6.13 & 0.014 & 1.33 \\
\hline 2-Way & 4 & 1.6858 & 0.42144 & 16.98 & 0.000 & \\
C*E & 1 & 0.4283 & 0.42826 & 17.25 & 0.000 & 4.08 \\
C*G & 1 & 1.5186 & 1.51865 & 61.18 & 0.000 & 2.60 \\
C*K & 1 & 0.1418 & 0.14176 & 5.71 & 0.018 & 2.48 \\
G*H & 1 & 0.6591 & 0.65908 & 26.55 & 0.000 & 1.44 \\
\hline Error & 155 & 3.8476 & 0.02482 & & & \\
\hline Total & 170 & 30.1132 & & & & \\
\hline & & & & & & \\
\hline
\end{tabular}


and Two-Way Interaction. Besides, they were also supported by a high R-Square of $87.22 \%$. The final equation model established from the RSM analysis is shown in Equation 1.

$$
\begin{aligned}
Y 1= & 26519+0.02231(B)+188.4(C)-280.8(D)-41.2(E)+0.0714(F)- \\
& -10.54(G)-6.69(H)+6.62(K)+1.924\left(C^{2}\right)+1.226\left(D^{2}\right) \\
& +0.0452\left(E^{2}\right)-0.618(C E)+0.919(C G)-1.013(C K) \\
& +0.0750(G H)
\end{aligned}
$$

The Equation 1 shows that 8 out of 10 variables were considered in the final model. Although E (SHP Temperature), and K (Induced Draft Fan Power) were accepted with $\mathrm{P}$-Value $>0.05$, they were accepted to maintain the hierarchical order in the final RSM model. Hierarchical order was prioritized over P-Value in the RSM analysis to obtain a reliable final equation model (Gaitonde et al., 2017; Noordin et al., 2004; Tanaka et al., 2007). The hierarchical order prioritization in this analysis was supported by the high R-square at $87.22 \%$ compared to the advised R-square of $>75 \%$ (Haaland, 1989; Omar et al., 2009). Besides, the confidence level was also already set at $95 \%$ for all intervals throughout the RSM analysis in the Analyze Response Surface Design interface in Minitab.

The coefficient factors in the final equation model will be a good basis in understanding the operating behavior and the criticality for the significant variables towards the higher Y1 (Ethylene Yield). Figure 2 shows the Probability Plot for residuals conducted for data validation to the final equation model.

The P-Value from the Probability Plot for the residuals was observed at higher than 0.05 which was 0.571 . This high $\mathrm{P}$-Value represented a good data distribution and model prediction in explaining the validity of the final equation model. The residuals in this plot compared the predicted data from the equation model and the actual data in the studied plant used for the RSM analysis. The P-Value of higher than 0.05 validated the acceptance for the final equation models using the Historical DOE method in the RSM analysis.

Figure 3 shows the actual data versus the predicted data distribution using the final model generated from the RSM analysis. The data were uniformly distributed at the normal operating range in producing Y1 (Ethylene Yield) at 28.8\% - 29.5\%. However, as this study was conducted in the actual large scale plant, the process condition was observed fluctuating for the Y1 (Ethylene Yield) at 30.1 - 30.5\%. However, this data was accepted into the establishment of the RSM model due the data was observed normal and stable from the normality and stability verification conducted earlier. These data had also proven reliable from the high R-square value of $87.2 \%$ in the final model regardless the study was conducted with the fluctuating process condition at the studied olefin plant. 


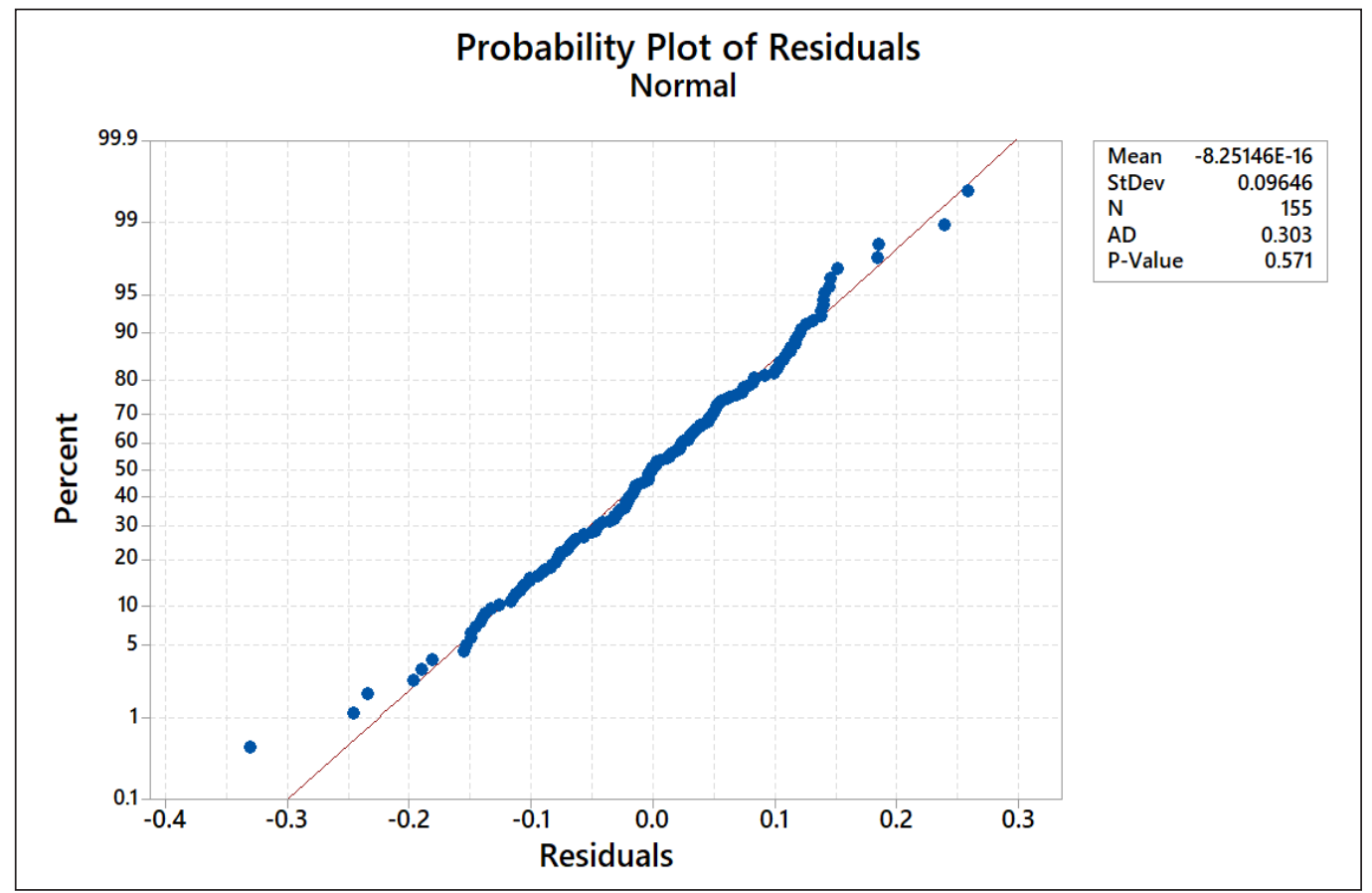

Figure 2. Validation using Probability Plot for the final equation model residuals

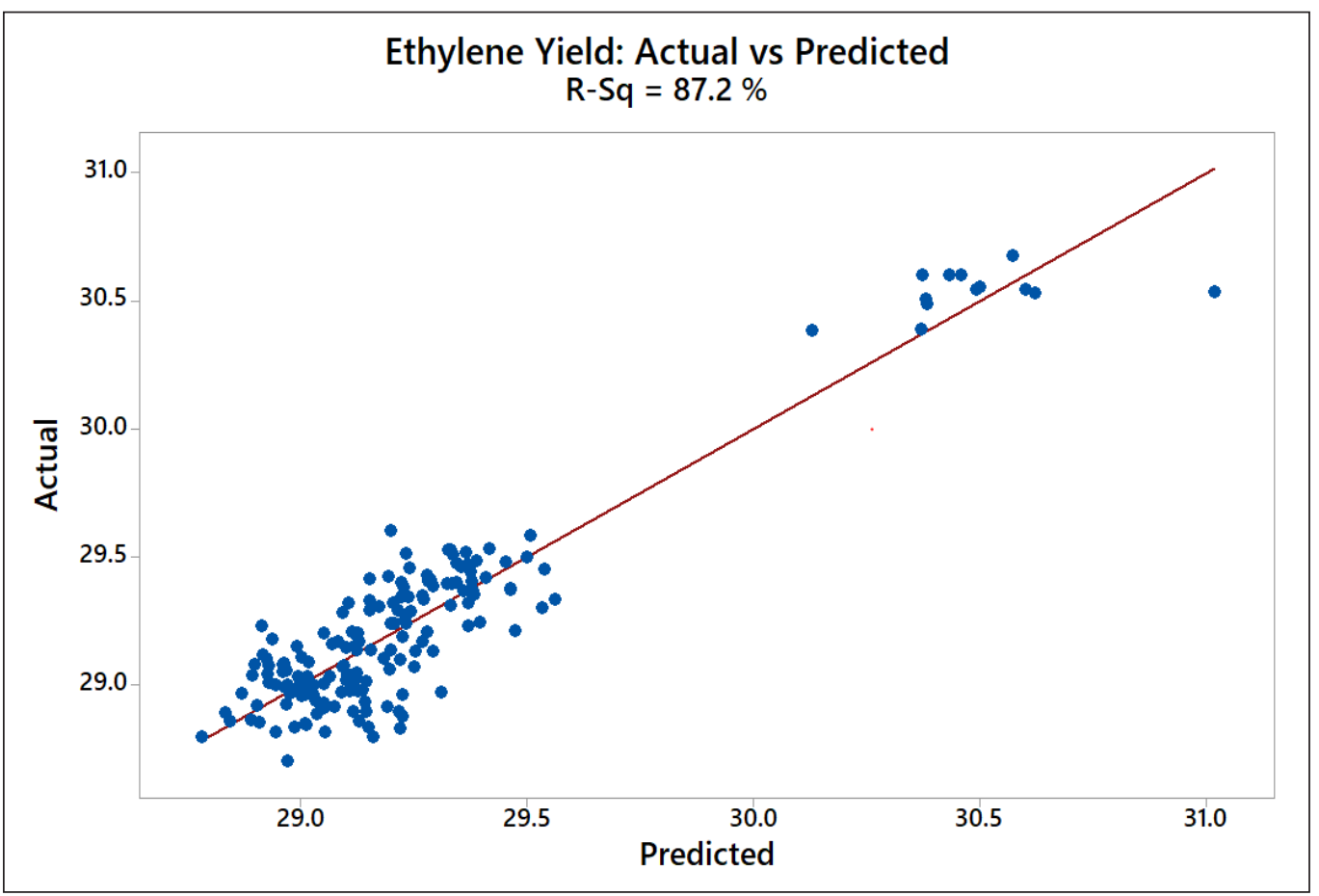

Figure 3. Actual vs predicted value for Y1 (Ethylene yield) 
Figure 4 shows the Surface Plot of variables with 4 highest coefficient factors in the equation model in achieving Y1 (Ethylene Yield) which were 188.4 of C (Arch $\left.\mathrm{O}_{2}\right),-280.8$ of D (Steam Drum Pressure), -41.2 of E (SHP Temperature), and -10.54 of G (SHP Flow).

The value for non-tested variables was held at mean value, $\overline{\mathrm{x}} ; 6.38 \%$ of $\mathrm{C}\left(\operatorname{Arch~} \mathrm{O}_{2}\right)$, 114.05 Barg of D (Steam Drum Pressure), $499.29{ }^{\circ} \mathrm{C}$ of E (SHP Temperature), and 90.50

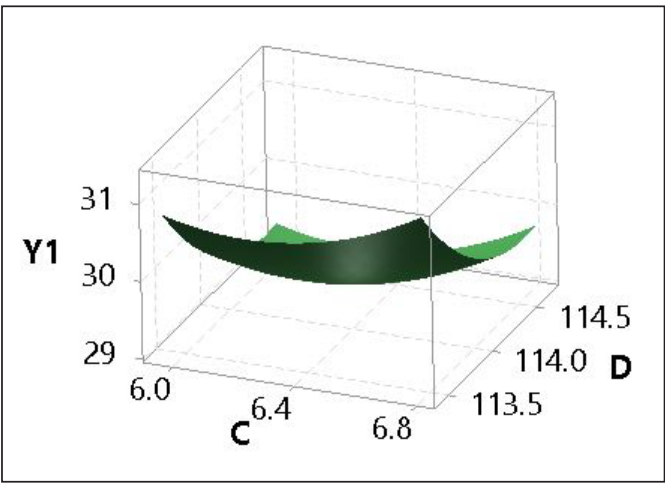

(a)

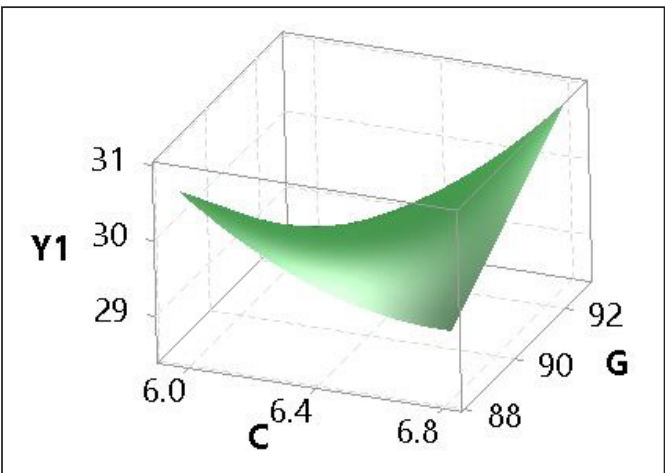

(c)

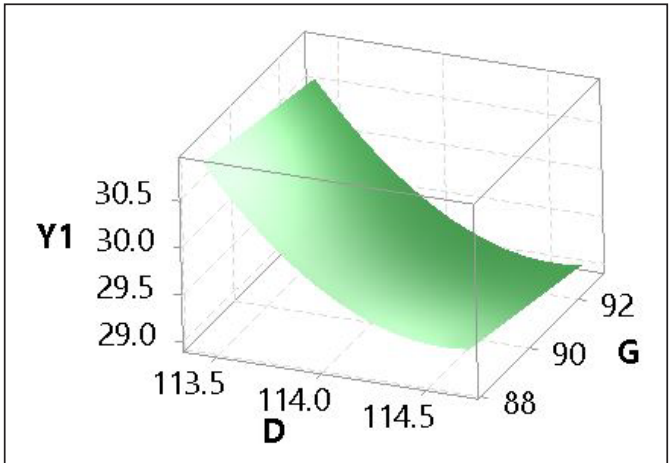

(e)

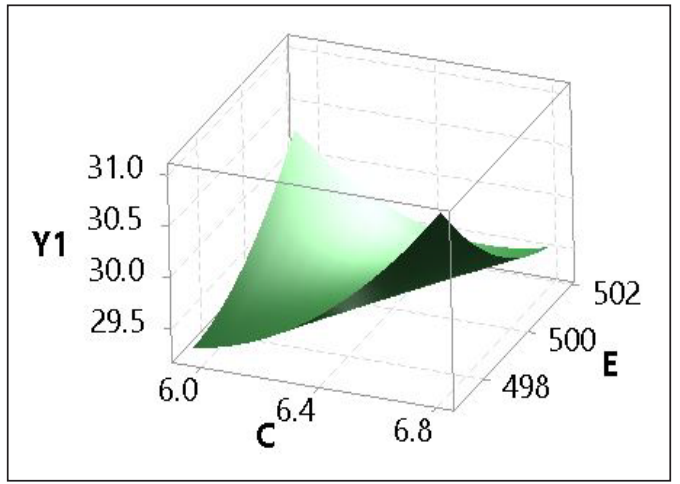

(b)

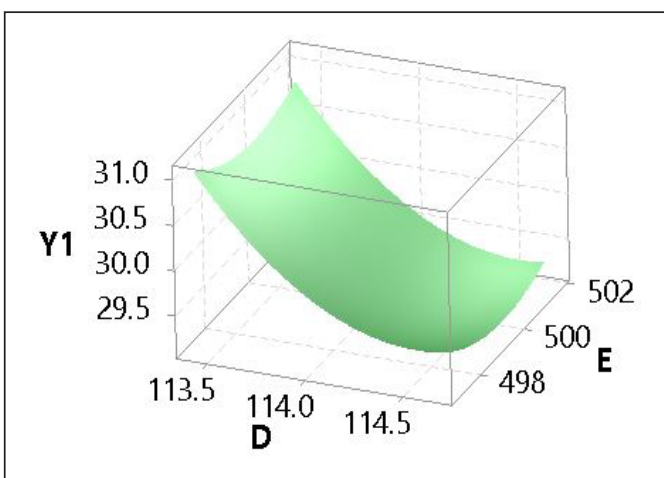

(d)

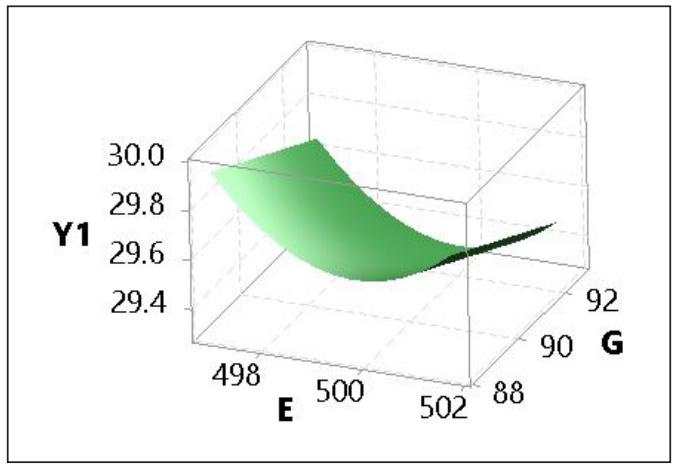

(f)

Figure 4. Surface Plot for most impactful variables towards Y1; (a) C vs D, (b) C vs E, (c) C vs G, (d) D vs E, (e) D vs G, and (f) E vs G 
$\mathrm{t} / \mathrm{h}$ of G (SHP Flow). The light on the Surface Plot was also set to indicate Y1 (Ethylene Yield) value at maximum.

Figure 4 (a) and 4 (b) indicate the higher value of $\mathrm{C}\left(\mathrm{Arch} \mathrm{O}_{2}\right)$ combined with the lower value of D (Steam Drum Pressure) or E (SHP Temperature) will result in higher Y1 (Ethylene Yield). However, operating the studied SRT VII with higher E (SHP Temperature) also will result in higher Y1 (Ethylene Yield) due to its significant quadratic relation that exists in the model compared to E (SHP Temperature). It was also good to note that operating the plant with the combination of lower $\mathrm{C}\left(\mathrm{Arch} \mathrm{O}_{2}\right)$ and lower $\mathrm{E}$ (SHP Temperature) should be avoided to prevent the poor Y1 (Ethylene Yield) as shown in the Surface Plot.

Figure 4 (c) illustrates the existence of both quadratic and cubic relations between $\mathrm{C}$ (Arch $\mathrm{O}_{2}$ ) and $\mathrm{G}$ (SHP Flow). Operating the plant with lower $\mathrm{C}\left(\mathrm{Arch} \mathrm{O}_{2}\right)$ combined with the lower G (SHP Flow) will favor the higher Y1 (Ethylene Yield). However, the higher Y1 (Ethylene Yield) may also be obtained via operating the higher $\mathrm{C}\left(\mathrm{Arch} \mathrm{O}_{2}\right)$ and $\mathrm{G}$ (SHP Flow).

Figure 4 (d), and 4 (e) show the same relation between D (Steam Drum Pressure) vs E (SHP Temperature) and D (Steam Drum Pressure) vs G (SHP Flow). Maximum Y1 (Ethylene Yield) can be achieved by manipulating the lower D (Steam Drum Pressure) for both variables. In these plots, both E (SHP Temperature) and G (SHP Flow) did not show significant impact when combined with D (Steam Drum Pressure) in achieving the targeted Y1 (Ethylene Yield).

Figure 4 (f) demonstrates that manipulating lower E (SHP Temperature) with lower G (SHP Flow) may also result in the higher Y1 (Ethylene Yield). However, Y1 (Ethylene Yield) will also reduce after reaching a certain operating condition of E (SHP Temperature) due to its quadratic relation as shown in the surface plot.

Table 3 displays the result of Multiple Response Prediction utilizing the RSM analysis in Minitab Software while Figure 5 shows the Response Optimizer evaluation for the process condition taken from the identified 8 significant variables to achieve the maximized Y1 (Ethylene Yield).

In general, the Response Optimizer result showed that Y1 (Ethylene Yield) could be maximized at $34.1 \%$ with the controlled operating range as illustrated in Figure 5. The recommended process setting for the highest identified coefficient in Equation 1, D (Steam

Table 3

Multiple Response Prediction for final equation model

\begin{tabular}{llccc}
\hline \multirow{2}{*}{ Response } & \multirow{2}{*}{ Fit } & \multirow{2}{*}{ Standard Error Fit } & \multicolumn{2}{c}{ Confidence $(95 \%)$} \\
\cline { 4 - 5 } & & & Confidence Interval & Prediction Interval \\
\hline Y1 & 34.096 & 0.420 & $(33.267,34.925)$ & $(33.210,34.982)$ \\
\hline
\end{tabular}




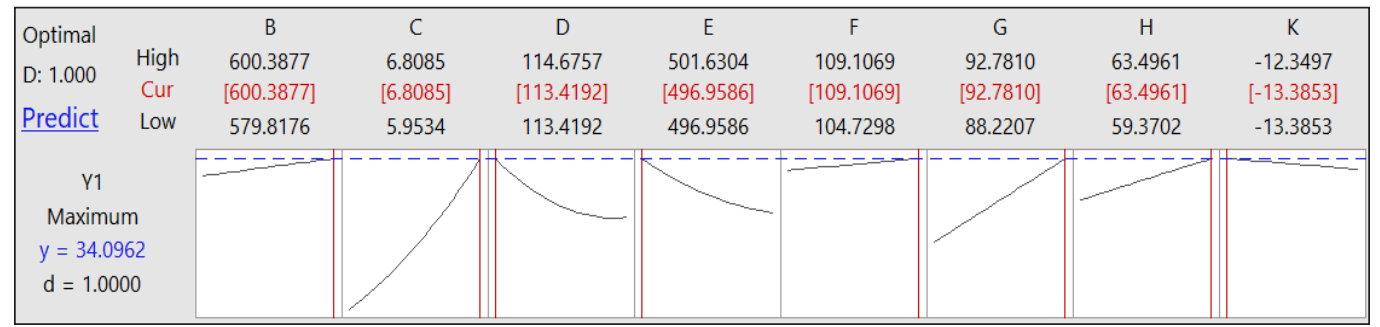

Figure 5. Process condition to achieve maximized Y1 from Response Optimizer

Drum Pressure) was 113.42 Barg. This value favored towards the lowest reading of D (Steam Drum Pressure) which was supported by a huge negative coefficient factor of - 288 in the equation model. The setting for the $2^{\text {nd }}$ biggest coefficient factor, $\mathrm{C}\left(\mathrm{Arch} \mathrm{O}_{2}\right)$ was identified at the highest side of $6.81 \%$. This setting explained the big positive coefficient factor of 188.4 for $\mathrm{C}\left(\mathrm{Arch} \mathrm{O}_{2}\right)$.

Figure 5 is helpful as a guide to control the process range condition at studied SRT VII for a better Y1 (Ethylene Yield) with a 95\% confidence level. The High and Low range setting in Figure 5 also can be referred to by Panel Operators and Operations Engineers in the studied plant to maximize the Y1 (Ethylene Yield).

Operating the furnace at a higher Coil Outlet Temperature (COT) was normally practiced by olefin plants worldwide to improve the ethylene yield. It was also recommended from various studies and reviews (Fakhroleslam \& Sadrameli, 2019; Fakhroleslam \& Sadrameli, 2020; Nabavi et al., 2009; Nabavi et al., 2011; Sadrameli, 2015; Song \& Tang, 2018). However, it is interesting that COT was not identified as the significant variable in this study. Besides COT, another interesting finding was Hearth Burner Flow that was widely studied also did not show significant relation to ethylene yield in this study (Han et al., 2016; Yu et al., 2018; Zhang et al., 2017).

Previous studies conducted widely using simulation software with a focus on only controlled variables such as COT and fuel gas consumption at burners without full consideration on the inter-related variables in the furnace. For example, Steam Drum Pressure which shown the highest coefficient factor in the final equation model was not discussed widely in the literature compared to the COT and other controlled variables. This due to Steam Drum Pressure is not a primary control variable and therefore it was less attractive for the optimization improvement studies.

RSM was proven a robust statistical tool in finding the significant relations for each identified variable in the studied SRT VII. Although COT and Hearth Burner Flow were not listed as one of the significant variables, the final equation model showed that the highest coefficient was contributed by Arch $\mathrm{O}_{2}$, Steam Drum Pressure, SHP Temperature, and SHP Flow. These 4 variables were highly dependent on the operating temperature inside the steam cracker furnace which is normally controlled by the COT and Hearth Burner Flow. 
However, as this study was conducted with the removal of VIF $>10$ to reduce multicollinearity in the final equation model, the highly inter-related variables were removed and the more significant variables were taken for the establishment of the reliable final equation model. If the analysis was conducted without removal of the variable with VIF $>10$, the COT and Hearth Burner Flow may exist in the final model as significant variables. However, it may not yield a reliable final equation model due to the huge multicollinearity factor that existed.

The approach in the study for the establishment of a reliable ethylene yield model was proven successful from the high R-square obtained at $87.22 \%$ and high P-Value of 0.571 for Probability Plot of the residuals. These were observed regardless of the study was conducted in the actual large scale olefin plant that came with process fluctuation. This study also showed that less attractive variables in the steam cracker furnace should not be neglected in the optimization study in achieving a higher ethylene yield.

\section{CONCLUSION}

The RSM analysis was successfully conducted at the studied plant utilizing Minitab Software Version 18. The Ethylene Yield can be maximized at $34.10 \%$ with the optimized value of $600.39 \mathrm{~kg} / \mathrm{hr}$ of Integral Burner Flow, 6.81\% of Arch $\mathrm{O}_{2}, 113.42$ Barg of Steam Drum Pressure, $496.96{ }^{\circ} \mathrm{C}$ of SHP Temperature, $109.11 \mathrm{t} / \mathrm{hr}$ of SHP BFW Flow, $92.78 \mathrm{t} /$ hr of SHP Flow, $63.50 \mathrm{t} / \mathrm{hr}$ of Naphtha Feed Flow, and -13.38 mmHg of Draft Pressure.

\section{ACKNOWLEDGMENTS}

The authors would like to acknowledge Pengerang Refining Company Sdn Bhd for providing robust tools and reliable equipment for data collection, analysis, and model validation. Besides, a special thank is also dedicated to Universiti Teknologi Malaysia for the academic support and advice in completing this study.

\section{REFERENCES}

Akah, A., \& Al-Ghrami, M. (2015). Maximizing propylene production via FCC technology. Applied Petrochemical Research, 5(4), 377-392. https://doi.org/10.1007/s13203-015-0104-3

Akporiaye, D., Jensen, S., Olsbye, U., Rohr, F., Rytter, E., Rønnekleiv, M., \& Spjelkavik, A. I. (2001). A Novel, Highly Efficient Catalyst for Propane Dehydrogenation. Industrial \& Engineering Chemistry Research, 40(22), 4741-4748. https://doi.org/10.1021/ie010299+

Amirov, N., \& Vakhshouri, A. R. (2020). Numerical modeling and optimization of product selectivity and catalyst activity in Fischer-Tropsch synthesis via response surface methodology: Cobalt carbide particle size and H2/CO ratio effects. International Journal of Hydrogen Energy, 45(56), 31913-31925. https:// doi.org/10.1016/j.ijhydene.2020.08.219 
Astruc, D. (2005). The Metathesis Reactions: From a Historical Perspective to Recent Developments. New Journal of Chemistry, 29(1), 42-56. https://doi.org/10.1039/b412198h

Belinskaya, N., Altynov, A., Bogdanov, I., Popok, E., Kirgina, M., \& Simakov, D. S. A. (2019). Production of Gasoline Using Stable Gas Condensate and Zeoforming Process Products as Blending Components. Energy \& Fuels, 33(5), 4202-4210. https://doi.org/10.1021/acs.energyfuels.9b00591

Berreni, M., \& Wang, M. (2011). Modelling and dynamic optimization of thermal cracking of propane for ethylene manufacturing. Computers \& Chemical Engineering, 35(12), 2876-2885. https://doi. org/10.1016/j.compchemeng.2011.05.010

Caballero, D. Y., Biegler, L. T., \& Guirardello, R. (2015). Simulation and optimization of the ethane cracking process to produce ethylene. Computer Aided Chemical Engineering, 37, 917-922. https://doi.org/10.1016/ B978-0-444-63578-5.50148-1

Cai, Y., Yang, S., Fu, S., Zhang, D., \& Zhang, Q. (2017). Investigation of portevin-Le chatelier band strain and elastic shrinkage in al-based alloys associated with $\mathrm{Mg}$ contents. Journal of Materials Science \& Technology, 33(6), 580-586. https://doi.org/10.1016/j.jmst.2016.05.012

Darvishi, A., Davand, R., Khorasheh, F., \& Fattahi, M. (2016). Modeling-based optimization of a fixed-bed industrial reactor for oxidative dehydrogenation of propane. Chinese Journal of Chemical Engineering, 24(5), 612-622. https://doi.org/10.1016/j.cjche.2015.12.018

Dente, M., Ranzi, E., \& Goossens, A. G. (1979). Detailed prediction of olefin yields from hydrocarbon pyrolysis through a fundamental simulation model (SPYRO). Computers \& Chemical Engineering, 3(1), 61-75. https://doi.org/10.1016/0098-1354(79)80013-7

Epstein, L. G. (1978). The Le Chatelier Principle in optimal control problems. Journal of Economic Theory, 19(1), 103-122. https://doi.org/10.1016/0022-0531(78)90058-3

Fakhroleslam, M., \& Sadrameli, S. M. (2019). Thermal/catalytic cracking of hydrocarbons for the production of olefins; a state-of-the-art review III: Process modeling and simulation. Fuel, 252, 553-566. https://doi. org/10.1016/j.fuel.2019.04.127

Fakhroleslam, M., \& Sadrameli, S. M. (2020). Thermal cracking of hydrocarbons for the production of light olefins: A review on optimal process design, operation, and control. Industrial \& Engineering Chemistry Research, 59(27), 12288-12303. https://doi.org/10.1021/acs.iecr.0c00923

Feli, Z., Darvishi, A., Bakhtyari, A., Rahimpour, M. R., \& Raeissi, S. (2017). Investigation of propane addition to the feed stream of a commercial ethane thermal cracker as supplementary feedstock. Journal of the Taiwan Institute of Chemical Engineers, 81, 1-13. https://doi.org/10.1016/j.jtice.2017.10.025

Gaitonde, V. N., Manjaiah, M., Maradi, S., Karnik, S. R., Petkar, P. M., \& Paulo Davim, J. (2017). Multiresponse optimization in wire electric discharge machining (WEDM) of HCHCr steel by integrating response surface methodology (RSM) with differential evolution (DE). In J. P. Davim (Ed.), Computational Methods and Production Engineering (pp. 199-221). Woodhead Publishing.

Geng, Z., Wang, Z., Zhu, Q., \& Han, Y. (2016). Multi-objective operation optimization of ethylene cracking furnace based on AMOPSO algorithm. Chemical Engineering Science, 153, 21-33. https://doi. org/10.1016/j.ces.2016.07.009 
Haaland, P. D. (1989). Experimental design in biotechnology. Marcel Dekker.

Hair, J. F., Anderson, R. E., Tatham, R. L., \& Black, W. C. (1995). Multivariate data analysis with readings (4th Ed.). Prentice-Hall.

Han, Y., Geng, Z., Wang, Z., \& Mu, P. (2016). Performance analysis and optimal temperature selection of ethylene cracking furnaces: A data envelopment analysis cross-model integrated analytic hierarchy process. Journal of Analytical and Applied Pyrolysis, 122, 35-44. https://doi.org/10.1016/j.jaap.2016.10.025

Hillewaert, L. P., Dierickx, J. L., \& Froment, G. F. (1988). Computer generation of reaction schemes and rate equations for thermal cracking. AIChE Journal, 34(1), 17-24. https://doi.org/10.1002/aic.690340104

Joo, E., Lee, K., Lee, M., \& Park, S. (2000). CRACKER - a PC based simulator for industrial cracking furnaces. Computers \& Chemical Engineering, 24(2), 1523-1528. https://doi.org/10.1016/S00981354(00)00558-5

Joo, E., \& Park, S. (2001). Pyrolysis Reaction Mechanism for Industrial Naphtha Cracking Furnaces. Industrial \& Engineering Chemistry Research, 40(11), 2409-2415. https://doi.org/10.1021/ie000774o

Karimi, H., Cowperthwaite, E., Olayiwola, B., Farag, H., \& McAuley, K. (2017). Modelling of heat transfer and pyrolysis reactions in an industrial ethylene cracking furnace. Canadian Journal of Chemical Engineering, 96(1), 33-48. https://doi.org/10.1002/cjce.22844

Karimzadeh, R., Godini, H. R., \& Ghashghaee, M. (2009). Flowsheeting of steam cracking furnaces. Chemical Engineering Research and Design, 87(1), 36-46. https://doi.org/10.1016/j.cherd.2008.07.009

Kee, R. J., Rupley, F. M., Miller, J. A., Coltrin, M. E., Grcar, J. F., Meeks, E., Moffat, H. K., Lutz, A. E., Dixon-Lewis, G., Smooke, M. D., Warnatz, J., Evans, G. H., Larson, R. S., Mitchell, R. E., Petzold, L. R., Reynolds, W. C., Caracotsios, M., Stewart, W. E., Glarborg P., .. \& Puduppakkam, K. V. (2006). CHEMKIN Release 4.1. SReaction Design.

Kuritsyn, V., Arapov, D., Ekimova, A., \& Yakupov, A. (2008). Modeling of pyrolysis of straight-run naphtha in a large-capacity type SRT-VI furnace. Chemistry and Technology of Fuels and Oils, 44(3), 180-189. https://doi.org/10.1007/s10553-008-0038-x

Masoumi, M., Sadrameli, S. M., Towfighi, J., \& Niaei, A. (2006). Simulation, optimization and control of a thermal cracking furnace. Energy, 31(4), 516-527. https://doi.org/10.1016/j.energy.2005.04.005

Montgomery, D. C. (2017). Design and analysis of experiments (8th Ed.). John Wiley \& Sons.

Nabavi, S., Rangaiah, G., Niaei, A., \& Salari, D. (2009). Multiobjective optimization of an industrial LPG thermal cracker using a first principles model. Industrial \& Engineering Chemistry Research, 48(21), 9523-9533. https://doi.org/10.1021/ie801409m

Nabavi, S., Rangaiah, G., Niaei, A., \& Salari, D. (2011). Design optimization of an LPG thermal cracker for multiple objectives. International Journal of Chemical Reactor Engineering, 9(1), 1-34. https://doi. org/10.1515/1542-6580.2507

Nian, X., Wang, Z., \& Qian, F. (2015). Strategy of changing cracking furnace feedstock based on improved group search optimization. Chinese Journal of Chemical Engineering, 23(1), 181-191. https://doi. org/10.1016/j.cjche.2014.09.027 
Noordin, M. Y., Venkatesh, V. C., Sharif, S., Elting, S., \& Abdullah, A. (2004). Application of response surface methodology in describing the performance of coated carbide tools when turning AISI 1045 steel. Journal of Materials Processing Technology, 145(1), 46-58. https://doi.org/10.1016/S0924-0136(03)00861-6

Omar, W. N. N. W., Nordin, N., Mohamed, M., \& Amin, N. A. S. (2009). A two-step biodiesel production from waste cooking oil: Optimization of pre-treatment step. Journal of Applied Sciences, 9(17), 3098-3103. https://doi.org/10.3923/jas.2009.3098.3103

Peller, A., Jambor, B., Hájeková, E., Hudec, P., Hadvinová, M., \& Horňáček, M. (2018). Hydrogenation of liquid hydrocarbon fractions for production of non-conventional diesel fuel. Petroleum and Coal, 60(6), 1112-1119.

Podrojková, N., Orinak, A., Oriňáková, R., Procházková, L., Čuba, V., Patera, J., \& Smith, R. (2018). Effect of different crystalline phase of $\mathrm{ZnO} / \mathrm{Cu}$ nanocatalysts on cellulose pyrolysis conversion to specific chemical compounds. Cellulose, 25(10), 5623-5642. https://doi.org/10.1007/s10570-018-1997-7

Reddy, P. V., Reddy, B., \& Ramulu, P. (2020). Mathematical modelling for prediction of tube hydroforming process using RSM and ANN. International Journal of Industrial and Systems Engineering, 35(1), 13-27. https://doi.org/10.1504/IJISE.2020.106848

Reyniers, P. A., Schietekat, C. M., Kong, B., Passalacqua, A., Van Geem, K. M., \& Marin, G. B. (2017). CFD simulations of industrial steam cracking reactors: Turbulence-chemistry interaction and dynamic zoning. Industrial \& Engineering Chemistry Research, 56(51), 14959-14971. https://doi.org/10.1021/ acs.iecr.7b02492

Sadrameli, S. M. (2015). Thermal/catalytic cracking of hydrocarbons for the production of olefins: A state-ofthe-art review I: Thermal cracking review. Fuel, 140, 102-115. https://doi.org/10.1016/j.fuel.2014.09.034

Sadrameli, S. M. (2016). Thermal/catalytic cracking of liquid hydrocarbons for the production of olefins: A state-of-the-art review II: Catalytic cracking review. Fuel, 173, 285-297. https://doi.org/10.1016/j. fuel.2016.01.047

Shi, H., Su, C., Cao, J., Li, P., Liang, J., \& Zhong, G. (2015). Nonlinear adaptive predictive functional control based on the Takagi-Sugeno model for average cracking outlet temperature of the ethylene cracking furnace. Industrial \& Engineering Chemistry Research, 54(6), 1849-1860. https://doi.org/10.1021/ ie $503531 z$

Song, G., \& Tang, L. (2018). Optimization model for the transfer line exchanger system. Computer Aided Chemical Engineering, 44, 1015-1020. https://doi.org/10.1016/B978-0-444-64241-7.50164-6

Song, H., Su, C. L., Shi, H., Li, P., \& Cao, J. T. (2019). Improved predictive functional control for ethylene cracking furnace. Measurement and Control, 52(5-6), 526-539. https://doi.org/10.1177/0020294019842602

Sun, Y., Yang, G., Li, K., Zhang, L., \& Zhang, L. (2016a). CO2 mineralization using basic oxygen furnace slag: process optimization by response surface methodology. Environmental Earth Sciences, 75(19), 1-10. https://doi.org/10.1007/s12665-016-6147-7

Sun, Y., Zhang, J., \& Zhang, L. (2016b). $\mathrm{NH}_{4} \mathrm{Cl}$ selective leaching of basic oxygen furnace slag: Optimization study using response surface methodology. Environmental Progress \& Sustainable Energy, 35(5), 13871394. https://doi.org/10.1002/ep.12365 
Tanaka, T., Sakai, K., Yamashita, Y., Sakamoto, N., \& Koyamada, K. (2007). Hierarchical response surface methodology for parameter optimization: Efficiency of a hierarchical RSM with a hessian matrix. In K. Koyamada, S. Tamura, \& O. Ono (Eds.), Systems Modeling and Simulation (pp. 213-217). Tokyo, Japan: Springer Japan.

Toufighi, J., Karimzadeh, R., Saedi, G., Hosseini, S., Morafahi, M., Mokhtarani, B., Niaee, A., \& Sadr, A. M. (2004). SHAHAB-A PC-based software for simulation of steam cracking furnaces (Ethane and Naphtha). Iranian Journal of Chemical Engineering, 1(2), 55-70.

Van Cauwenberge, D. J., Vandewalle, L. A., Reyniers, P. A., Van Geem, K. M., Marin, G. B., \& Floré, J. (2017). Periodic reactive flow simulation: Proof of concept for steam cracking coils. AIChE Journal, 63(5), 1715-1726. https://doi.org/10.1002/aic.15530

Van de Vijver, R., Vandewiele, N. M, Bhoorasingh, P. L., Slakman, B. L., Khanshan, F. S., Carstensen, H. H., Reyniers, M. F., Marin, G. B., West, R. H., \& Van Geem, K. M. (2015). Automatic mechanism and kinetic model generation for gas- and solution-phase processes: A perspective on best practices, recent advances, and future challenges. International Journal of Chemical Kinetics, 47(4), 199-231. https://doi. org/10.1002/kin.20902

Van Geem, K., Reyniers, M., \& Marin, G. (2008). Challenges of modeling steam cracking of heavy feedstocks. Oil \& Gas Science and Technology, 63(1), 79-94. https://doi.org/10.2516/ogst:2007084

Van Goethem, M. W. M., Kleinendorst, F. I., van Leeuwen, C., \& van Velzen, N. (2001). Equation-based SPYRO ${ }^{\circledR}$ model and solver for the simulation of the steam cracking process. Computers \& Chemical Engineering, 25(4), 905-911. https://doi.org/10.1016/S0098-1354(01)00655-X

Vangaever, S., Reyniers, P. A., Symoens, S. H., Ristic, N. D., Djokic, M. R., Marin, G. B., \& Van Geem, K. M. (2020). Pyrometer-based control of a steam cracking furnace. Chemical Engineering Research and Design, 153, 380-390. https://doi.org/10.1016/j.cherd.2019.10.023

Willems, P. A., \& Froment, G. F. (1988). Kinetic modeling of the thermal cracking of hydrocarbons. 1. Calculation of frequency factors. Industrial \& Engineering Chemistry Research, 27(11), 1959-1966. https://doi.org/10.1021/ie00083a001

Yu, K., While, L., Reynolds, M., Wang, X., Liang, J. J., Zhao, L., \& Wang, Z. (2018). Multiobjective optimization of ethylene cracking furnace system using self-adaptive multiobjective teaching-learningbased optimization. Energy, 148, 469-481. https://doi.org/10.1016/j.energy.2018.01.159

Zakria, M. H., Omar, A. A., \& Bustam, M. A. (2016). Mercury removal of fluctuating ethane feedstock in a large scale production by sulphur impregnated activated carbon. Procedia Engineering, 148, 561-567. https://doi.org/10.1016/j.proeng.2016.06.511

Zhang, Y., Reyniers, P. A., Du, W., Qian, F., Van Geem, K. M., \& Marin, G. B. (2017). Incident radiative heat flux based method for the coupled run length simulation of steam cracking furnaces. Industrial \& Engineering Chemistry Research, 56(14), 4156-4172. https://doi.org/10.1021/acs.iecr.6b05013 